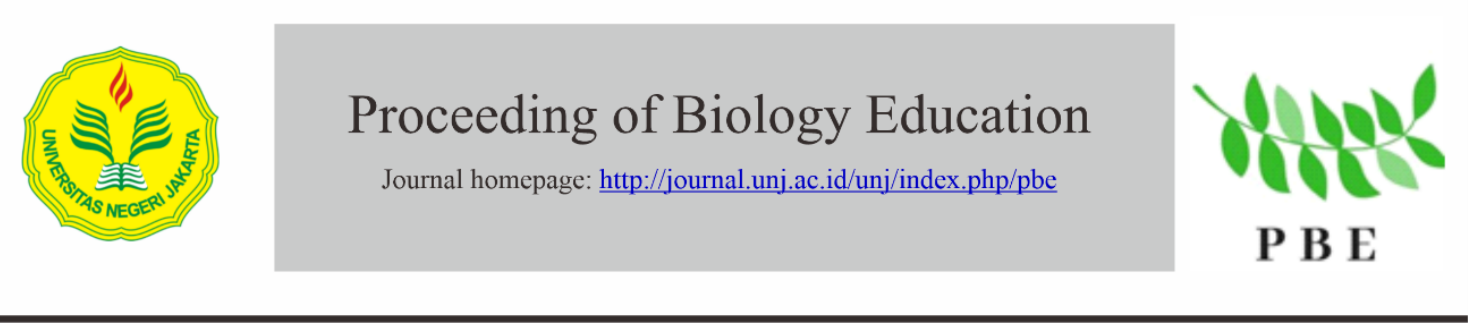

\title{
Perbanyakan Jabon Merah (Anthocephallus macrophyllus (Roxb.) Havil) Secara Vegetatif dengan Stek Pucuk Muda dan Stek Pucuk Tua (tunas wiwilan) dengan Zat Pengatur Tumbuh
}

\author{
Ely Kristiati Agustin \\ Pusat Konservasi Tumbuhan Kebun Raya Bogor-LIPI \\ *Coresponding author: ely_kristiati@yahoo.com
}

\section{ART I CLE INF O}

Article history:

Received: 22 Agustus 2018

Accepted: 12 September 2019

\section{Keywords:}

Jabon merah, vegetatif, stek, ZPT

\begin{abstract}
ABSTRAK
Jabon merah(Anthocephallus macrophylus) merupakan salah satu anggota keluarga kopi-kopian (Rubiaceae). Tumbuhan ini tergolong jenis tanaman hutan yang cepat tumbuh (fast growing species). Pada umumnya pengembangan kayu jabon diperuntukan sebagai bahan baku pulp dan kertas, kayu lapis, mebeler, bahan bangunan dan konstruksi ringan. Beberapa tahun belakangan ini laju perkembangan industri perkayuan terhambat terkait dengan berbagai masalah yang dihadapi saat ini, salah satu permasalahan utamanya adalah pasokan kayu. Mengingat lajunya kebutuhan kayu ini kiranya diperlukan salah satu materi genetik perbanyakan vegetatif. Perbanyakan vegetatif mempunyai beberapa keunggulan, diantaranya adalah tidak bergantung pada musim buah, efektif dalam perbanyakan secara masal dan mempunyai keturunan yang sifat genetiknya sama dengan induknya. Rancangan percobaan yang digunakan adalah Rancangan Acak Kelompok (RAK) dengan 2 faktor. Faktor pertama yaitu pengaruh pemberian Rootone-f. Faktor kedua adalah asal bahan stek. Teknik perbanyakan vegetatif merupakan salah satu alternatif untuk memperbanyak jenis tanaman ini. Penelitian ini bertujuan untuk mengetahui pengaruh pemberian zat pengatur tumbuh dan asal sumber stek juvenil muda dan tunas wiwilan jabon merah. Hasil penelitian menunjukkan bahwa Rootone-f memberikan pengaruh signifikan terhadap persen berakar tunas muda $(98,67 \%)$ dan stek pucuk tua $(74,67 \%)$. Demikian pula tumbuh akar paling cepat yaitu pada hari ke-4 setelah tanam. Persentase stek hidup adalah $91,58 \%$.
\end{abstract}

\section{PENDAHULUAN}

Jabon merah (Anthocephalus macrophyllus) merupakan salah satu jenis indigenous yang potensial. Tumbuhan ini masuk kedalam keluarga Rubiaceae (kopi-kopian). Masyarakat mengenal jabon merah dengan nama lokal Samama khususnya di daerah Maluku. Tumbuhan ini berasal dari daerah muson tropis seperti Indonesia, Malaysia, 
Thailan dan Philiphina. Penyebaran alami jabon merah di Indonesia meliputi Sulawesi, Maluku, dan Papua. Ada dua jenis jabon yang saat ini dikenal masyarakat yaitu jabon putih dan jabon merah. Jabon putih memiliki daging kayu yang berwarna putih sedangkan daging kayu jabon berwarna merah seperti daging kayu meranti. Harga kayu jabon merah lebih mahal dibandingkan jabon putih. Pada umumnya pengembangan Jabon diperuntukan sebagai bahan baku pulp dan kertas, kayu lapis, mebeler, bahan bangunan dan konstruksi ringan. Jabon merah lebih disukai petani karena memiliki beberapa keunggulan diantaranya kayunya lebih keras, memiliki daun lebih lebar dan tidak terlihat bekas ketiak daun pada kayu batangnya ketika dipanen. Lebih tahan terserang hama dan penyakit. Penelitian ini bertujuan untuk mengetahui pengaruh pemberian zat pengatur tumbuh dan asal sumber stek juvenil muda dan tunas wiwilan jabon merah.

Permasalahan yang dihadapi dunia industri perkayuan sampai saat ini, salah satunya adalah kurangnya akan pasokan kayu. Menurut Ramayanti et. al 2009; Mindawati et. al. (2010) menyatakan bahwa jabon merah merupakan salah satu jenis tanaman kayu yang mendapat prioritas dalam pembangunan hutan tanaman penghasil kayu. Tanaman ini tergolong cepat tumbuh, umur 6 (enam) tahun dengan kondisi budidaya yang baik mampu tumbuh mencapai tinggi $18 \mathrm{~m}$ dan diameter batang $42 \mathrm{~cm}$ (Halawane et al., 2011). Tekstur kayunya halus dengan warna merah yang unik, kerapatan 3 serat $0,55 \mathrm{~g} / \mathrm{cm}$, kadar air $16 \%$, keteguhan lentur 2 tatis $260,75 \mathrm{~kg} / \mathrm{cm}$, keteguhan tekan serat $189,982 \mathrm{~kg} / \mathrm{cm}$ (Abdurachman \& Hadjib, 2009). Mengingat lajunya kebutuhan kayu ini kiranya diperlukan salah satu materi genetik perbanyakan vegetatif. Perbanyakan vegetatif mempunyai beberapa keunggulan, diantaranya adalah tidak bergantung pada musim buah, efektif dalam perbanyakan secara masal dan mempunyai keturunan yang sifat genetiknya sama dengan induknya. Rootone-F merupakan hormon pemacu pertumbuhan akar tanaman. Rootone-F terdiri atas senyawa-senyawa yang menjadi bahan aktifnya yaitu 1-naphtaleneacetamide (NAD) 0,067\%, 2-methyl-1-naphtalene-acetic acid (MNAA) 0,333\%, 3-methyl1-naphtalene-acetamide (MNAD) 0,013\%, indole-3-butiric acid (IBA) 0,051\% serta tetramethyl-thiuram disulfide (Thiram) 4\%. Dengan memperhatikan komposisi bahan aktif yang ada dalam Rootone-F tersebut maka Rootone-F tidak digolongkan dalam hormon tetapi lebih tepat sebagai zat pengatur tumbuh karena kandungan Thiram yang relatif tinggi dibandingkan bahan aktif lainnya (Manurung, 1987). Penggunaan Rootone-F lebih efektif merangsang perakaran dari pada penggunaan hanya satu jenis hormon secara tunggal pada konsentrasi sama (Supriyanto dkk., 2011).

\section{METODE}

Metode yang digunakan pada penelitian ini adalah Rancangan Acak Kelompok dengan 2 faktor. Faktor pertama yaitu pengaruh pemberian zat pengatur tumbuh sedangkan faktor kedua adalah sumber bahan stek yang digunakan pada penelitian ini. Data penelitian diperoleh dari jumlah stek berakar dari sumber bahan stek yang berbeda.

\section{Metode Pengumpulan Data}

Bahan utama dalam pembuatan stek pucuk adalah pucuk atau tunas tanaman. Pucuk yang diambil adalah pucuk - pucuk yang masih dalam keadaan juvenile. Ada 2 sumber stek yaitu stek pucuk yang diambil dari bibit jabon ukuran 10-15 $\mathrm{cm}$ stek ini disebut sebagai stek muda Gambar 1 (a). Sedangkan pada stek yang berasal dari tunas wiwilan yang tumbuh pada tangkai plagiotrop pada pohon jabon yang tingginya 3 meter (Gambar 1b) disebut sebagai stek tua.

Pembuatan stek dilakukan dengan cara memotong pucuk -pucuk juvenile dengan panjang 2 internodus. Kemudian pucuk-pucuk yang telah di potong dimasukkan kedalam wadah berisi air yang sudah diberikan anti stres selama 20 menit. Cara memotong pangkal batang stek dilakukan miring dengan tujuan agar bidang terbentuknya akar lebih banyak. Dalam pemotongan secara melintang ini digunakan cutter yang tajam agar pada saat 
pemotongan pangkal batang stek tidak pecah karena apabila terjadi pecah maka akan menyebabkan kerusakan jaringan sel pada bagian bawah stek yang akan ditanam. Pada bahan stek yang sudah dipotong dilakukan pengurangan dan pemotongan daun hanya disisakan $1 / 3$ bagian dengan tujuan untuk mengurangi penguapan. Selanjutnya stek diolesi dengan ZPT (Rootone-F) yang sudah dibuat dalam bentuk pasta, kemudian ditanam pada polybag yang sudah diisi dengan madia tanah, kompos, cocopeat dengan perbandingan 1:2:1. Masing-masing perlakuan terdiri atas tiga ulangan. Setiap ulangan terdiri dari 25 stek pucuk.

Stek ditanam sedalam $1 / 3$ bagian pada polibag yang sudah terisi media. Polibag yang digunakan untuk stek pucuk juvenil muda yaitu ukuran $10 \times 12 \mathrm{~cm}$ sedangkan untuk stek tua yang berasal dari tunas wiwilan menggunakan polibag yang ukuran $12 \times 12 \mathrm{~cm}$ Selanjutnya diberi sungkup plastik agar kelembaban terjaga.

\section{Metode Analisis Data}

Metode analisis data dilakukan dengan menghitung persentase jumlag stek yang hidup pada stek pucuk tanaman Jabon muda dan stek pucuk yang berasal tanaman Jabon yang tua. Selain itu dihitung juga berapa lama waktu yang diperlukan untuk tumbuhnya akar pada masing-masing bahan stek.

\section{Persen Stek Hidup (PSH)}

Persentase stek hidup dilakukan dengan menghitung jumlah stek yang hidup pada akhir percobaan. Rumus yang digunakan:

$$
\text { PSH }=\underbrace{\text { Jumlek yang ditanam }}_{\text {Jumlah Stek Hidup }} \times 100 \%
$$

Lama waktu muncul akar dilakukan dengan cara mengamati berapa lama akar muncul pada pangkal stek.

\section{HASIL DAN PEMBAHASAN}

Persentase hidup merupakan perbandingan antar jumlah tanaman yang hidup pada akhir penelitian dengan jumlah tanaman yang ditanam pada awal penelitian. Perbanyakan tanaman secara vegatatif dengan stek dianggap berhasil apabila sudah tumbuh akar. Pada Gambar 2. ditampilkan persentase stek pucuk berakar. Stek pucuk muda yang diberi perlakuan ZPT menghasilkan jumlah persentase berakar lebih tinggi yaitu 98,67 \% , sedangkan stek pucuk tua yang berasal dari juvenil tunas wiwilan menghasilkan persentase hidup lebih rendah $(74,67 \%)$. Hal ini menunjukkan bahwa persentase hidup stek muda yang diberi perlakuan lebih tinggi daripada stek yang berasal dari tunas wiwilan. Kandungan auksin pada pucuk tanaman yang kurang dari satu meter persentasenya lebih tinggi dibandingkan diatas satu meter. Menurut Gardner, dkk(1991) bahwa auksin diproduksi dalam jaringan meristimatik yang aktif terutama pada pada pucuk muda dan tunas. Mahlstede and Haber (1976) juga menyatakan bahwa kemampuan stek membentuk akar merupakan bukti tingkat perkembangan jaringan tanaman. Perlakuan Rootone-F berpengaruh nyata terhadap persen stek hidup. Hal ini sesuai dengan pernyataan Rismunandar (1988) bahwa ZPT dapat mempercepat tumbuhnya organ penting tanaman seperti akar, batang dan daun. Demikian pula tanpa perlakuan (kontrol) jumlah stek pucuk muda yang berakar lebih tinggi (72\%) sedangkan stek pucuk tua $56 \%$.

Tabel 1. Waktu pertumbuhan stek berakar 


\begin{tabular}{|l|c|c|}
\hline \multicolumn{1}{|c|}{ Perlakuan } & Stek muda (hari) & Stek tua (hari) \\
\hline ZPT & 4 & 8 \\
\hline Kontrol (tanpa perlakuan) & 11 & 18 \\
\hline
\end{tabular}
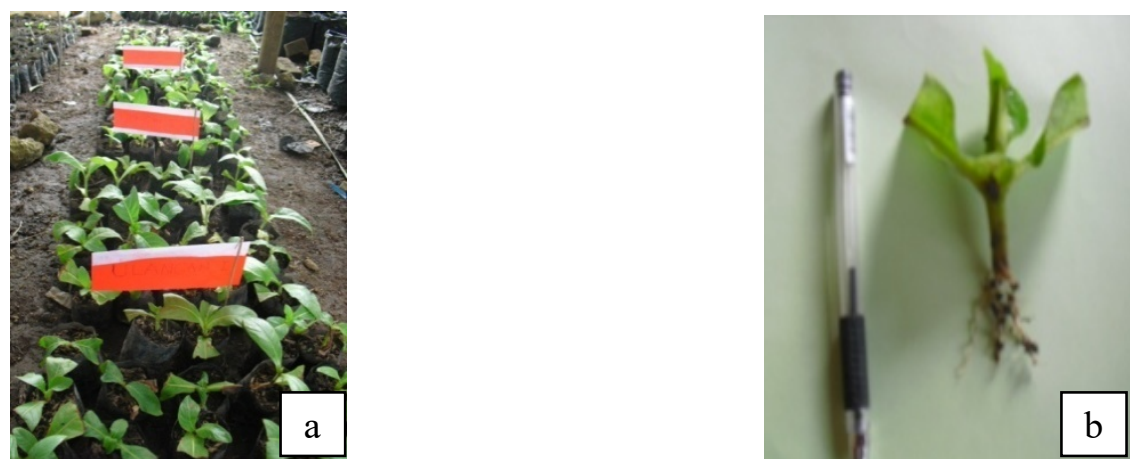

Gambar 1. Hasil perbanyakan stekjabon

Keterangan:

(a). Stek muda

(b). Stek tua

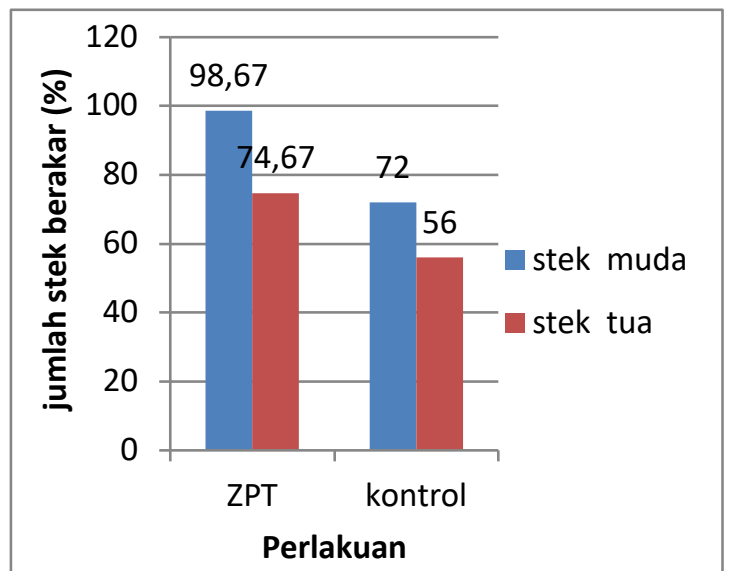

Gambar 2. Diagram persen stek berakar

Berdasarkan analisa laboratorium yang dilakukan Danu (2015) stek jabon merah mengandung hormon auksin alami (Indole acetic acid atau IAA) 0,0077 ppm. Akinyale (2010) memaparkan hal serupa bahwa auksin alami yang dihasilkan oleh tanaman meskipun dalam konsentrasi rendah namun mampu mengatur proses fisiologis pertumbuhan tanaman itu sendiri. Pemberian Rootone-F sebagai ZPT berpengaruh nyata terhadap pertumbuhan akar stek jabon muda maupun stek jabon tua dibandingkan dengan kontrol(Gambar. 2). Gardner et.al. (1991) mengungkapkan bahwa auksin mempunyai pengaruh yang nyata terhadap pertumbuhan pucuk. Pada Tabel 1 dapat dilihat perbedaan waktu muncul akar antara stek muda yang diberi ZPT dibandingkan dengan kontrol. Pada stek muda yang diberi perlakuan mulai tumbuh akar pada hari ke4 sedangkan yang tidak diberi perlakuan tumbuh akar 11 hari setelah tanam (HST). Demikian pula pada stek jabon tua yang diberi perlakuan tumbuh akar pada hari ke-8 sedangkan tanpa perlakuan hari ke-18 setelah tanam. Hal ini menunjukkan bahwa pada stek muda yang diberi perlakuan dan tanpa perlakuan lebih cepat berakar. Meskipun demikian pengaruh ZPT memberikan hasil yang signifikan. Pengamatan dilapangan menunjukkan stek yang berasal dari organ. Hal ini dinyatakan Prawiranata et. al. 
(1992) bahwa auksin diproduksi dalam jumlah besar di bagian pucuk dan ditranspor secara polar ke bagian bawah tanaman (basipetal). Komposisi auksin berubah secara gradual dari bagian pucuk, bagian batang yang masih membesar hingga bagian batang yang telah tua.

Dari hasil pengamatan dan seleksi persentase stek berakar pada akhir penelitian ternyata ditemukan kondisi akar stek muda yang mulai membusuk berwarna coklat sehingga hal ini akan menimbulkan kematian bagi stek tersebut. Hal ini diduga karena kelembaban yang tinggi pada ruang sungkup sehingga stek pucuk tersebut terlalu lembab dan menimbulkan jamur. Jumlah stek yang kondisinya akarnya membusuk $7 \%$ dari stek hidup sehingga persentase stek hidup pada akhir penelitian adalah 91,58 \%.

\section{KESIMPULAN}

Dari hasil penelitian dapat disimpulkan perbanyakan vegetatif jabon merah dengan stek juvenil muda dengan perlakuan zat pengatur tumbuh Rootone-F menghasilkan stek hidup tertinggi ( $91,58 \%$ ) dengan waktu stek berakar paling cepat yaitu 4 hari setelah stek ditanam.

\section{DAFTAR PUSTAKA}

Abdurachman \& Hadjib (2009) dalam Danu et.al. 2015. Pertumbuhan stek jabon merah (Anthocephallus macrophyllus(Roxb.)(Havil) pada berbagai media dan Zat pengatur

Akinyale. (2010). Effects of growth hormones, rooting media media and leaf size on juvenile stem cuttings of Buchholzia coriacea Engler. Ann. Res., 53(2),127133

Danu et.al. (2015). Pertumbuhan stek jabon merah (Anthocephallus macrophyllus(Roxb.)(Havil) pada berbagai media dan Zat pengatur tumbuh. Jurnal penelitian tanaman hutan vol. 12 .

Gardner F. P., R. B. Pearce, R. L. Mitchell, (1991). Fisiologi Tanaman Budidaya. Terjemahan H. Susilo. UI Press. Jakarta.

Halawane J.E., Hidayah H.N., \& Kinho, J. (2011). Prospek Pengembangan Jabon Merah (Anthocehallus macrophyllus (Roxb.) Havil). Solusi Kebutuhan Kayu Masa Depan. Balai Penelitian Menado.

Mahlstede, J. P. \& T. L. E. S. Haber. (1976). Plant Propagation. Jhon Wiley and Sons Inc. New York. 413p.

Manurung, S. O. (1987). Status dan potensi Zat Pengatur Tumbuh Serta Penggunaan Rootone-F Dalam Perbanyakan Tanaman. Makalah Seminar Rootone-F ; Ditjen Reboisasi dan Rehabilitasi Lahan, Dept. Kehutanan. Jakarta. 83 hal

Ramayanti, S., Suhartati, \& Aprianis, Y. (2009). Potensi Jenis Tanaman Lokal Sebagai Alternatif Bahan Baku Pulp. Gelar Teknologi Badan Litbang Kehutanan. Tahun 2009.

Mindawati, N., Bogidarmanti, R., Nuroniah, H.S,. Kosasih, A.S., Suharti, Rahmayanti, S., Junaedi, A., Rahmat, E., \& Rochmayanto,Y. (2010). Silvikultur Jenis 
Alternatif Penghasil Kayu Pulp. Pusat Penelitian

Prawiranata, W., S. Harran \& P. Tjondronegoro. (1992). Diktat Kuliah Dasar -dasar FisiologiTumbuhan. Jurusan Biologi, Fakultas Matematika dan Ilmu Pengetahuan Alam. IPB. Bogor. 248 hal.

Rismunandar dalam Haryadi et.al,. (2017). Pengaruh Jenis Bahan Tanam dan Konsentrasi Rootone-F terhadap Keberhasilan Pertumbuhan Mucuna bracteata D.C. Buletin Agronomi 5 (2) : 226-233

Supriyanto \& Prakarsa, K. E. (2011). Pengaruh Zat Pengatur Tumbuh Rootone F Terhadap Pertumbuhan Stek Dua Bangsa mollucana. Blume. SilvikulturTropika. 3(1): 59-65. 